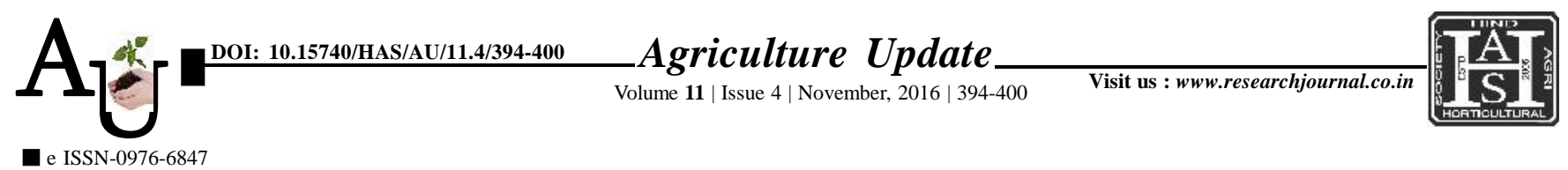

\title{
Research article: Analysis of entrepreneurial behaviour among vegetable growers at Bonli block of Sawai Madhopur district in Rajasthan
}

Article Chronicle:

Received :

01.08.2016;

Revised :

26.09.2016;

Accepted :

12.10.2016

KeY WoRds :

Entrepreneurial behaviour, Vegetable growers, Market orientation

\section{PRASHANT MARATHA, S.K. BADODIYA AND K.K. CHAURASIYA}

SUMMARY : Entrepreneurial behaviour of a farmer is influenced by several factors. The study was conducted purposively in Bonli block of Sawai madhopur district. The total of 200 vegetable growers were formed the sample for the study. The primary data were collected through personal interview method with the help of pre-tested interview schedule which was prepared on the basis of objectives of investigation and variables. The statistical tests and procedures were used for analyzing the data with the help of statistical tools like- mean, S.D., percentage and Karl Pearson's co-efficient of correlation, multiple correlation and regression analysis were used for analysis of data. Majority of the respondents $(61.00 \%)$ had medium level of entrepreneurial behaviour. All the 13 selected attributes of vegetable growers, were found positive and significant relationship with entrepreneurial behaviour of vegetable growers except age, caste and mass media exposure. The major constraints expressed by vegetable growers were fluctuations in the market price (87.50\%).

How to cite this article : Maratha, Prashant, Badodiya, S.K. and Chaurasiya, K.K. (2016). Analysis of entrepreneurial behaviour among vegetable growers at Bonli block of Sawai Madhopur district in Rajasthan. Agric. Update, 11(4): 394-400; DOI : 10.15740/HAS/AU/11.4/394-400.
Author for correspondence :

\section{PRASHANT MARATHA}

Rajmata Vijayaraje

Scindia Krishi

Vishwavidyalaya,

GWALIOR (M.P.) INDIA

Email:prashantmaratha

@ gmail.com

See end of the article for

authors' affiliations 